\title{
RECUPERANDO EL CONCEPTO DE DISPONIBILIDAD EN LA CLÍNICA PSICOLÓGICA
}

\section{Recovering the availability of clinical healthcare}

\author{
Maria Adela Bertella* \\ Universidad Austral - Buenos Aires, Argentina \\ https://orcid.org/0000-0001-5719-7877
}

\begin{abstract}
Resumen
El tema de este trabajo es reflexionar y recuperar la importancia del concepto de disponibilidad como eje del trabajo terapéutico más allá del modelo clínico que enmarque la terapia. Se utilizaron como fuentes de referencia tanto autores clásicos como estudios actuales vinculados al desarrollo genuino de la persona. A partir de la disponibilidad del terapeuta hacia los puntos de tensión del paciente, el paciente podrá identificarse con esta actitud de alojar en sí mismo lo evitado, negado, rechazado y en definitiva quizás se pueda tratar a sí mismo en sus dificultades como siente que es tratado o alojado por su terapeuta. Que la persona del paciente pueda sacar su vivir del estancamiento que lo detiene y lo limita, y así reiniciarlo, implica ofrecerle la disponibilidad y no obligarlo a cumplir metas teóricas. Sacar del estancamiento aspectos de la vida para que el agua del desarrollo pueda seguir su curso hacia la propia verdad, la de su singularidad única.
\end{abstract}

Palabras clave: disponibilidad-verdadero y falso self-paradoja-modelos terapéuticos

\begin{abstract}
The aim of this study is to reflect upon and recapture the importance of availability as the axis of therapeutic work beyond its underlying clinical model. Both classical authors and current studies linked to the genuine development of the person were used as reference sources. From the therapist's availability towards the patient's points of tension, patients will be able to identify themselves with the attitude of lodging in what has been avoided, denied, or rejected; ultimately, they may become able to treat their own difficulties in the way they feel the therapist addresses them. For patients to step out of the stagnation that freezes their lives, and thus start afresh, they need to be offered availability without being forced to meet theoretical goals. This involves driving different aspects of life out of stagnation, and leading patients towards their own truth, that of their unique individuality.
\end{abstract}

Keywords: availability, true and false self, paradox, redevelopment, therapeutic models

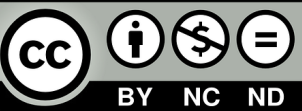

Cualquier uso que se haga de este artículo debe incluir: Autor / Título original de la publicación / ISSN.

* Psicóloga. mariaadelabertella@gmail.com 
Distintos estudios han comprobado que ningún modelo teórico es tanto mejor que otro ni que los resultados de las terapias especializadas difieren sustancialmente, y que la persona del analista a partir del vínculo que se construye con el paciente es el factor central promotor del cambio psíquico (Leichsenring \& Leibing, 2003; Levy et al., 2012). Livesley (2016) en la misma línea de los estudios mencionados, refiere que el $50 \%$ de la cura depende del paciente, el 10\% del modelo teórico y el $40 \%$ restante de la personalidad del terapeuta.

Por otra parte, el contexto que acompaña la circunstancia y el devenir de la persona ha sido en su historia y lo es en el presente, parte esencial en su vivir. En este sentido, investigaciones recientes (Henao López \& García Vega, 2009, Avondet, 2016; Barudy \& Dantagnan, 2010; Stassen Berger, 2016; Tuñón, 2015; Valencia \& Henao López, 2012) han dado evidencia científica de la importancia de las condiciones ambientales y de los vínculos con otros para mejorar o empeorar la calidad de vida de una persona. La interacción entre lo que cada persona trae en su constitución biológica y su entorno ambiental, va a generar diferentes pautas cognitivas, afectivas, vinculares y de comportamientos que podrán actuar como factores protectores o de riesgo.

A partir de los estudios que se centran en la importancia del ambiente, es que surge el interrogante de este ensayo. Dado que ningún modelo clínico es tanto mejor que otro y el factor vincular de la relación con el terapeuta/analista es decisivo... desde qué lugar podrían las distintas formas de abordaje convertirse en un buen ambiente facilitador para que el paciente pueda encontrarse consigo mismo y seguir desarrollándose desde el lugar propio en el que esté?

Winnicott nos enseña que el desarrollo genuino estaría vinculado en su constitución al gesto espontáneo del bebé, gesto que expresa la manera de ser única y propia de cada persona, pero que además se va construyendo en el intercambio amable con un cuidador que se lo facilite, dando lugar a un verdadero o genuino self (Winnicott, 1990). Sabemos que las circunstancias de un ambiente opuesto, o sea no amable, moldeador o restrictivo de las posibilidades propias, genera una potente defensa vincular que es resguardarse. De esta manera, para poder proteger lo propio la persona siente que debe acomodarse y no exponerse, ser cuasi sumiso hacia y con lo que el otro le exige, espera o impone, dando lugar al desarrollo del germen de un self falso, o dicho de otro modo a un sí mismo subjetivo (Stern, 1991), que en este caso respondería sobre adaptándose a las necesidades narcisistas del otro, reprimiendo al mismo tiempo el malestar, o la rabia que implica el no haber sido reconocido, aceptado o validado a partir de lo genuino o propio.

Vale aclarar, que existe y se necesita contar particularmente para la vida social en sus distintos espacios, con un falso self adaptado socialmente y regido por pautas socioculturales (Winnicott, 2007), pero este no sería el caso al que nos referimos. Nos referimos particularmente a un self construido predominantemente desde la sumisión, que se va acostumbrando a ser para otro y no para sí mismo, instaurándose podríamos decir casi como un hábito vincular, a partir de experiencias repetidas, de no poder identificar o valorar lo que se siente desde uno mismo dejándolo de lado para ser desde lo que el otro expresa como su necesidad.

Desde la clínica se observa cómo el encuentro vincular profundo también conlleva la implicancia de cierta renuncia a lo propio como por ejemplo sucede en los vínculos de pareja o con los mismos hijos, pero vale la pena agregar que estas renuncias implicarían un paso previo, y que ha tenido que recorrerse antes de la entrega misma, y es haber podido ser primero para uno mismo, en un sentido cuasi dialéctico. Pero aquí nos encontramos con la paradoja winnicottiana que Winnicott (1972) describe como un interjuego de tensión entre los contrarios, que no se resuelve unilateralmente y que implicaría identificar la tensión y justamente poder tolerarla para resolver creativamente lo que se presenta. En otras palabras, sería como dejar que el otro sea sin que uno deje de ser. Un aforismo que se le atribuye a Hilel (h. 110 a. C.-10 d. C.), pensador que desde épocas remotas hace alusión a esta cuestión inherente a la condición humana, dice así: Si yo no soy para mi, ¿quién será para mi? ¿Y si soy solo para mi... quién soy yo? El ser desde esta mirada se construiría entonces desde uno mismo y también con el otro. 
Continuando con esta reflexión, el yo genuino, el que surge inicialmente para sí mismo, el verdadero en el sentido winnicottiano, si no encuentra las condiciones para emerger, solo responderá de acuerdo con lo que se espera de él y no desde lo que siente como propio, generándose paulatinamente sentimientos de vacío y de indefensión. En este sentido la creatividad, lo original, lo que se pueda aportar de diferente, desde lo genuino, desde el actuar con convicción y entusiasmo, quedará ahogado y solo saldrá a la palestra del día a día la sumisión a la expectativa, deseo, pedido o exigencia del otro. No habría registro de lo propio y el no cumplir las expectativas ajenas sumirá a la persona en sentimientos de culpa, despersonalización, confusión o sensación de vacío. Podrá tener incluso logros y éxitos profesionales o económicos pero lo que queda al final del día es una sensación de ajenidad, de cierta falsedad o extrañamiento no pudiendo sentirse feliz por el logro obtenido.

Y aquí vale la pena recordar la definición de Winnicott (1967) sobre salud mental en la que ésta estaría vinculada a sentir que uno está viviendo su propia vida, a sentirse protagonista, de la propia historia, con los matices que incluya, tanto desde asumir las responsabilidades y los fracasos, así como gozar y apropiarnos de los logros.

Pero cuando una persona funciona en modo sumisión o de falso self y lo recibimos como paciente, es con este modo vincular con el que se puede conectar. ¿Se podrá entonces acompañar el desarrollo personal desde ese lugar o sea desde ese self oculto, desde lo que pudo quedar en su propio devenir detenido o ahogado? ¿Podrá quizás en algún momento conectarse con su deseo profundo y autentico, aquel que lo hace seguir viviendo?

¿Los distintos modelos terapéuticos, cualquiera sea, favorecen... o impiden que el paciente pueda (y desde donde pueda) apropiarse de lo propio, de lo genuino, del propio deseo?

Distintos modelos de abordaje, como el psicoanálisis e incluso las corrientes cognitivas más actuales, pueden con seguridad dar cuenta de estos interrogantes, pero la idea de este ensayo es intentar acercarse a pensarlas desde un concepto conocido, pero no por ello simple, que adquiere relevancia desde esta mirada, casi como una llave que marcaría el camino. Me refiero al concepto de disponibilidad. Si bien la idea de disponibilidad es un concepto milenario, actualmente se destaca como parte de las competencias específicas del psicólogo clínico más valoradas por profesores, alumnos y empleadores de psicólogos clínicos (Bertella, 2017)

Saber escuchar con preocupación sincera e interés para entrar en el mundo del paciente, ver y experimentar la vida como lo hace este respetando su marco de referencia, su cultura, sus costumbres, sus creencias, sus valores, su manera de percibir el mundo, estableciendo un clima de confianza, empatía, aceptación y colaboración. (Bertella, 2017).

Francois Jullien (2013) filólogo contemporáneo, describe la disponibilidad metafóricamente como un ir desarmándose como yo e ir implicándose con armonía en lo que el paciente nos transmite. Refiere que el modelo occidental de atención psicológica se centra solo en curar y con ese objetivo desatiende muchas veces la práctica de la disponibilidad.

Desarrollar la disponibilidad implicaría entonces la capacidad de captar lo que nos dicen sin adelantarnos a suponer desde la propia perspectiva, o sea, intentar entender y escuchar sin proyectar lo propio en el otro y desde ahí forzarse en querer convencerlo.

En este sentido la disponibilidad nos abre a un abanico de posibilidades de escucha y conexión con el otro sin rigideces o evasiones. Sería estar atentos a responder sin dejar de lado o desoír nada, y también estar atento a que lo personal del analista no obstaculice esa plasticidad. La atención flotante, técnica fundante ya descripta por Freud (1912), tendría también bordes en común con la actitud de disponibilidad. Si se logra esta actitud, el analista sin darse cuenta se irá abriendo a la diversidad y a la capacidad de aceptar lo inesperado en su paciente, sin perder de vista el sentido de oportunidad e interviniendo solo si es necesario. El adherirse a una posición rígida, funcionando a la manera de un ambiente moldeador (involuntario pero presente en nuestros modelos terapéuticos), quiebra la posibilidad de entrar en sintonía con el otro. 
La tendencia en esta época es posiblemente más a clasificar el sufrimiento humano que a rescatar la complejidad de la vida psíquica. La vida de las emociones y la constitución subjetiva estarían desde esta perspectiva, llenas de vicisitudes y vinculada al ambiente en que se ha producido el desarrollo infantil (Janin, 2011), ambiente que como se describió anteriormente, también puede desde sus sombras y exigencias llevar a la persona a la desconexión con el propio sentir, el propio deseo, con lo que genuinamente se necesita para desplegar lo singular en la vida.

La metáfora del agua que necesita correr y fluir y si hay algún hueco, éste debe llenarse antes para poder seguir su curso, nos acerca a la idea del camino inevitable y lleno de huecos del propio devenir personal de quien nos consulta. Es en ese sentido, que la disponibilidad que le ofrecemos sería acercarlo a una nueva oportunidad para re-desarrollarse en el sentido winnicottiano. Acompañar a un paciente en este sentido no es forzarlo a que haga o piense tal o cual cosa, tampoco es cuestión de solo buena voluntad, se trata más de recibir lo que trae y estar para esperar lo que tiene que llegar. Es central que el devenir y la transformación o el cambio en el propio recorrido personal, siga su propio curso, a su manera y a su tiempo, como lo hace el camino del agua (Beja, 1969).

De acuerdo con lo descrito es importante proveer vínculos terapéuticos que posibiliten que la persona encuentre lo propio, reflexione sobre ello y pueda intentar cambiar su rumbo vital cuando se encuentra paralizado en una frontera. Desandar este camino a partir de la consulta no resulta tarea sencilla, al contrario, es una tarea ardua, compleja, por momentos difícil o desalentadora. Muchas veces uno como terapeuta se ofrece más como una entelequia, desde un modelo rígido alistado en aplicar indicaciones de manuales.

Desde la persona del terapeuta es también importante tener en cuenta que puede también generarse y con cierta frecuencia, una especie de arco de tensión entre la disponibilidad que se desea transmitir y el posible no entender la narrativa del paciente, en estos casos, y tal como sugiere Winnicott, la clave no estaría en pretender resolverlo sino en poder vivir la tensión que nos implica, hasta encontrar el camino para que el agua, en este caso la propia, pueda seguir su curso. Es entonces que nuevamente vale la pena detenerse en la importancia de tolerar la paradoja entre nuestro no comprender y lo que el paciente hace, dice o siente, facilitando un espacio de reflexión y encuentro. El no entender al paciente se resuelve muchas veces caratulando apresuradamente, con categorías o modelos rígidos, Dicho con otras palabras, es imposible saltear las etapas o forzar la comprensión, la actitud es seguir el paso del proceso, de lo que se efectúa poco a poco y a su tiempo. Asî es como que cuando se llena la cavidad encontrada, el manantial naturalmente se desborda y el agua de la singularidad podrá seguir su curso, y por más mínima que sea cada gota, para la vida del paciente puede resultar altamente significativa.

A partir de la disponibilidad del terapeuta hacia los puntos de tensión del paciente, el paciente podrá identificarse con esta actitud de alojar en sí mismo lo evitado, negado, rechazado y en definitiva quizás se pueda tratar a sí mismo en sus dificultades como siente que es tratado o alojado por su terapeuta y dar cabida progresiva a lo propio. Que la persona del paciente pueda sacar su vivir del estancamiento que lo detiene y fija, y así reiniciarlo, esto implica ofrecerle la disponibilidad y no obligarlo a cumplir metas teóricas. Sacar del estancamiento aspectos de la vida para que el agua del desarrollo pueda seguir su curso hacia la propia verdad, la de su singularidad única.

\section{REFERENCIAS}

Avondet, L. (2016). Vulnerabilidad social, falta de sostén familiar: resiliencia como una capacidad a promover en intervenciones con niños y adolescentes en un primer nivel de atención Facultad de Psicología, Universidad de la República, Montevideo, Uruguay.

Barudy, J. y Dantagnan, M. (2010). Los desafios invisibles de ser madre o padre. Manual de evaluación de las competencias y la resiliencia parental. Gedisa 
Beja, F. B. (1969). Mencio: Sobre la naturaleza humana. Estudios Orientales, 4(3 (11)), 333-337. http://www.jstor.org/stable/40313905

Bertella, M. (2017). Las competencias en psicología clínica.Qué esperan los empleadores, quéenseñan los profesores y qué aprenden los alumnos. ISBN: 978-620-2-24164-9. Académica Española.

Freud, S (1912). "Consejos al médico sobre el tratamiento analítico", en Obras Completas Vol. XII. Amorrortu, 1980.

Henao López, G. C. \& García Vega, M. C. (2009). Interacción familiar y desarrollo emocional en niños y niñas. Revista Latinoamericana de Ciencias Sociales, niñez y juventud, 7(2), 785802.

Janin B. (2011). El sufrimiento psíquico en los niños Psicopatología infantil y constitución subjetiva. Colección Noveduc 2017

Jullien, F. (2013) Cinco conceptos propuestos al psicoanálisis. El cuenco de plata.

Leichsenring, F., \& Leibing, E. (2003). The effectiveness of psychodynamic therapy and cognitive behavior therapy in the treatment of personality disorders: a meta-analysis. The American journal of psychiatry, 160 (7), 1223-32.

Livesley, J., Dimaggio, G., Clarkin, J. (2016). Tratamiento integrado para el trastorno de la personalidad. Un enfoque modular. Guilford Press.

Stassen-Berger, K. (2016). Psicología del desarrollo: infancia y adolescencia. Médica Panamericana: $9^{\circ}$ edición.

Stern, D. N. (1991). El mundo interpersonal del infante: Una perspectiva desde el psicoanálisis y la psicología evolutiva. Paidos

Tuñón, I. (Coord.) (2015). Desafíos del desarrollo humano en la primera infancia. Biblos.

Valencia, L. I. y Henao López, G. C. (2012). Influencia del clima sociofamiliar y estilos de interacción parental sobre el desarrollo de habilidades sociales en niños y niñas. Persona, (15), 253-271.

Winnicott, D. (1967). El concepto de individuo sano. 1967. In Conferencia pronunciada en la División de Psicoterapia y Psiquiatría social de la real Asociación Medico-psicológica (Vol. 8).

Winnicott, D. W., \& Mazía, F. (1972). Realidad y juego. Gedisa.

Winnicott, D. W. (1990). El gesto espontáneo: Cartas escogidas. Paidós Ibérica.

Winnicott, D. W. (2007). Los procesos de maduración y el ambiente facilitador. Paidós.

Fecha de recepción: 21 de setiembre 2021

Fecha de aceptación: 1 de octubre 2021 